\title{
Peptide-based formula versus standard-based polymeric formula for critically ill children: is it superior for patients' tolerance?
}

\author{
Hanan Ibrahim, Mervat Mansour, Yasmin Gamal El Gendy
}

Ain Shams University, Cairo, Egypt

Submitted: 22 April 2017

Accepted: 17 August 2017

Arch Med Sci 2020; 16 (3): 592-596

DOI: https://doi.org/10.5114/aoms.2020.94157

Copyright @ 2020 Termedia \& Banach

\begin{abstract}
Introduction: Malnutrition affects $50 \%$ of hospitalized children and $25-70 \%$ of critically ill children. Enteral tube feeding is generally considered the preferred modality for critically ill pediatric patients. Clinical advantages of using peptide-based formulas are still controversial in critically ill children. The aim of this study was to compare the effect of a peptide-based formula versus a standard polymeric formula on feeding tolerance and whether this will affect the outcome among critically ill children.

Material and methods: This single blind case control study was conducted on 180 randomly selected critically ill children in the pediatric critical care unit (PICU) of Ain Shams University. Patients were divided into 2 groups: a group receiving a standard polymeric formula (group 1; 90 patients) and a group receiving a peptide-based formula (group II; 90 patients). Nutritional requirements, days to reach full enteral feeding, feeding intolerance symptoms and anthropometric measurements were recorded for all patients at admission together with their pediatric risk of mortality score (PRISM). Length of PICU stay, occurrence of sepsis together with survival were analyzed at discharge as outcome measures.

Results: Patients receiving a peptide-based formula showed a significant decrease in feeding interruptions and abdominal distention $(p<0.000)$, reached full enteral feeding faster $(2.60 \pm 0.74$ days versus $5.36 \pm 1.00$ days in patients received polymeric standard formula; $p<0.001)$ and improved weight gain $(p<0.028)$. Moreover, duration of sepsis was significantly shorter $(p<0.045)$, but no difference in mortality was recorded between patient groups.

Conclusions: Peptide-based formula feeding was better tolerated than standard polymeric formula feeding in critically ill pediatric patients. However, the choice of patients receiving the peptide-based formula needs to be further evaluated.
\end{abstract}

Key words: peptide-based, standard formula, critically ill children, feeding.

\section{Introduction}

Significant development in enteral formulas during the last several years has made enteral tube feeding the most common method of nutritional support for critically ill patients [1].

Nevertheless, the increasing variety of available enteral formulas may increase the risk of inadequate use of these products, especially those conceived for particular situations [2].

\author{
Corresponding author: \\ Yasmin Gamal El Gendy \\ Ain Shams University \\ New Cairo \\ 113881 Cairo, Egypt \\ E-mail: mervatgmansour@ \\ gmail.com
}


Peptide-based formulas contain proteins that have been hydrolyzed to produce peptides of varying lengths and are also referred to as "elemental" diets as well as "partially" or "semi-" elemental. As compared to whole-protein formulas, peptide-based formulas have been shown to: improve nitrogen retention/balance; improve visceral protein synthesis; improve absorption/reduce diarrhea; maintain/restore gut integrity; reduce bacterial translocation; and improve outcomes [3]. Peptide-based formula as a first enteral nutrition prescription was associated with greater severity of patients' clinical status, those receiving $\alpha$-adrenergic drugs or those who are malnourished [4]. Studies addressing the clinical advantages of using peptide-based formulas in critical illness were carried out in adult patients and the results were controversial [5]. Still no clear recommendations are available on the use of peptide-based formulas in critically ill children. A recent pilot study suggested that feeding a peptide-based formula to intensive care unit (ICU) patients may be associated with a statistically significant reduction in the number of days during which adverse events occurred as compared to a standard formula [6].

The aim of this study was to compare the effect of a peptide-based formula versus a standard polymeric formula on enteral feeding tolerance of pediatric ICU patients and record possible effects on patient outcome.

\section{Material and methods}

This single blind case control study was conducted in a pediatric ICU (PICU), Ain Shams University Cairo, Egypt from June 2014 to June 2015. The study was approved by the pediatric hospital board and written consent was obtained from the parents of enrolled children.

Patients admitted to the PICU above 1 year of age, hemodynamically stable and who started enteral tube feeding within $24 \mathrm{~h}$ were included while patients with a dysfunctional gastrointestinal tract were excluded. One hundred eighty patients were enrolled and randomized to two groups. Group 1 included 90 patients who received enteral feeding with a standard polymeric formula. Group 2 included 90 patients who received a peptide-based formula. Standard and whole protein formulas were considered polymeric.

All patients were followed by 3 intensivists and a pediatric nutritionist for the study period.

The following parameters were recorded at admission: patients' age and gender, PRISM score, medical diagnosis.

Nutritional assessment was done for all patients including: weight for age, body mass index, skin fold thickness and mid-arm circumference both at admission and at discharge, z-scores were calculated and all data were plotted on WHO growth charts for age [7].

Nutritional assessment was done during the PICU stay and included: intake, requirements and resting energy expenditure (REE), days of nothing per os (NPO), days to reach full intake, signs of feeding intolerance (gastrointestinal bleeding, ileus, gastroesophageal reflux and abdominal distention). Frequency, duration and causes of feeding interruption were observed and time needed for reintroduction of feeding was recorded for all the patients.

Outcome measures were observed as regards fate of the patients (died or discharged alive), days of mechanical ventilation, and length of PICU stay, sepsis days and use of vasopressor agents if any.

\section{Statistical analysis}

Data were collected, revised, coded and entered in SPSS Statistics version 20. The qualitative data were presented as number and percentages while the quantitative data were presented as mean, standard deviations and ranges for the parametric data.

The comparison between two groups with qualitative data were done using the $\chi^{2}$ test and/ or Fisher's exact test only when the expected count was less than 5 .

The comparison between two independent groups with quantitative data and parametric distribution were done using the independent $t$-test while the comparison between two paired groups with quantitative data and parametric distribution were done using the paired $t$-test.

The confidence interval was set to $95 \%$ and the margin of error accepted was set to $5 \%$. So, the $p$-value was considered significant if $<0.05$.

\section{Results}

Demographic and clinical characteristics of patients showed male predominance in both studied groups with mean age $3.33 \pm 2.96$ years in the peptide-based formula group versus $2.52 \pm 1.68$ years in the standard formula group. The main cause of PICU admission was bronchopneumonia in both groups. Predicted mortality risk assessed by PRISM score was $16 \pm 7.21$ in the peptide formula group versus $17 \pm 4.41$ in the standard formula group with no significant difference $(p=0.955)$ (Table I).

Nutritional assessment during the study showed that patients on the peptide-based formula gained weight on termination of the study while patients on the standard formula even lost weight by the end of the study period $(0.19 \pm 0.44 \mathrm{~kg}$ vs. -0.04 $\pm 0.21 \mathrm{~kg}, p=0.045)$. Mean resting energy expenditure was $743.85 \pm 236.27 \mathrm{kcal}$ in patients receiving 
Table I. Demographic and clinical characteristics of studied population

\begin{tabular}{|lccc|}
\hline Parameter & $\begin{array}{c}\text { Patients on standard formula } \\
(n=90)\end{array}$ & $\begin{array}{c}\text { Patients on peptide-based } \\
\text { formula }(n=90)\end{array}$ & $P$-value \\
\hline Gender, male, $n(\%)$ & $63(70.0)$ & $51(56.6)$ & 0.284 \\
\hline Age, mean \pm SD [years] & $3.33 \pm 2.96$ & $2.52 \pm 1.68$ & 0.194 \\
\hline \begin{tabular}{l} 
Cause of PICU admission, $n$ (\%): \\
\hline Status epilepticus
\end{tabular} & $9(10.0)$ & $12(13.3)$ & \\
\hline Bronchopneumonia & $51(56)$ & $36(39.6)$ & \\
\hline Encephalitis & $6(6.7)$ & $9(10.0)$ & \\
\hline Septic shock & $9(10.0)$ & $6(6.7)$ & $6(6.7)$ \\
\hline Colon bypass & $3(3.3)$ & $6(6.7)$ & \\
\hline Polytrauma & $3(3.3)$ & $9(10.0)$ & $6(6.7)$ \\
\hline Heart failure & $6(6.7)$ & $0-24$ & \\
\hline Bronchial asthma & $3(3.3)$ & $0-22$ & \\
\hline PRISM score & & & \\
\hline
\end{tabular}

the standard formula and $657.95 \pm 203.98 \mathrm{kcal}$ in patients receiving the peptide-based formula with no statistically significant difference.

We calculated days of fasting before starting enteral feeding and it was $2.43 \pm 1.17$ days in patients receiving the standard formula and 2.75 \pm 4.39 days in patients on the peptide-based formula ( $p=0.704$ ) with no significant difference.

Patients in the peptide-based formula group reached their full oral caloric intake faster than the standard formula group ( $2.60 \pm 0.74$ days vs. 5.36 \pm 1.00 days) ( $p=0.001)$ with significantly fewer feeding interruptions ( $1.73 \pm 1.32$ vs. $4.26 \pm 1.61)$ in the standard formula group $(p=0.000)$ (Table II).

The main causes of feeding interruption were increased gastric residual volumes and gastric distention and to a lesser extent vomiting and hematemesis, all of which showed a significantly higher percentage in the standard formula group compared to the peptide-based formula (Table II).

Table II. Nutritional follow-up of both groups

\begin{tabular}{|c|c|c|c|}
\hline Parameter & $\begin{array}{l}\text { Patients on standard } \\
\text { formula }\end{array}$ & $\begin{array}{l}\text { Patients on peptide-based } \\
\text { formula }\end{array}$ & $P$-value \\
\hline Weight gain during PICU stay, mean \pm SD [kg] & $-0.04 \pm 0.21$ & $0.19 \pm 0.44$ & 0.045 \\
\hline Resting energy expenditure, mean \pm SD & $743.85 \pm 236.27$ & $657.95 \pm 203.98$ & 0.137 \\
\hline $\begin{array}{l}\text { Interval from NPO to starting enteral } \\
\text { feeding, mean } \pm \text { SD [days] }\end{array}$ & $2.43 \pm 1.17$ & $2.75 \pm 4.39$ & 0.704 \\
\hline $\begin{array}{l}\text { Duration to reach full caloric requirements, } \\
\text { mean } \pm S D \text { [days] }\end{array}$ & $5.36 \pm 1.00$ & $2.60 \pm 0.74$ & 0.001 \\
\hline $\begin{array}{l}\text { Frequency of feeding interruption, } \\
\text { mean } \pm \text { SD [days] }\end{array}$ & $4.26 \pm 1.61$ & $1.73 \pm 1.32$ & 0.001 \\
\hline $\begin{array}{l}\text { Duration of feeding interruption, } \\
\text { mean } \pm \text { SD [days] }\end{array}$ & $13.26 \pm 4.55$ & $8.60 \pm 4.81$ & 0.001 \\
\hline \multicolumn{4}{|l|}{ Forms of feeding intolerance: } \\
\hline Increase gastric residual volume (>50\%) & $60(66.70 \%)$ & $12(13.30 \%)$ & 0.001 \\
\hline Abdominal distention & $60(66.70 \%)$ & $3(3.30 \%)$ & 0.001 \\
\hline Vomiting & $21(23.30 \%)$ & $3(3.30 \%)$ & 0.023 \\
\hline Hematemesis & $36(40 \%)$ & $12(13.3 \%)$ & 0.020 \\
\hline \multicolumn{4}{|l|}{ Interruption of feeding due to systemic cause: } \\
\hline Extubation from mechanical ventilation & $27(30.00 \%)$ & $39(43.30 \%)$ & 0.284 \\
\hline Septic shock & $15(16.70 \%)$ & $9(10.00 \%)$ & 0.448 \\
\hline Systemic bleeding & $27(30.00 \%)$ & $3(3.30 \%)$ & 0.006 \\
\hline
\end{tabular}


Table III. Outcome analysis between both groups

\begin{tabular}{|lccc|}
\hline Outcome & $\begin{array}{c}\text { Patients on standard } \\
\text { formula }\end{array}$ & $\begin{array}{c}\text { Patients on peptide-based } \\
\text { formula }\end{array}$ & $P$-value \\
\hline Sepsis, mean \pm SD [days] & $7.33 \pm 5.11$ & $4.50 \pm 4.59$ & 0.028 \\
\hline Mechanical ventilation, mean \pm SD [days] & $6.77 \pm 5.11$ & $5.17 \pm 5.75$ & 2.25 \\
\hline Length of PICU stay, mean \pm SD [days] & $11.83 \pm 3.24$ & $12.80 \pm 6.93$ & 0.491 \\
\hline Mortality, $n(\%)$ & $33(36)$ & $27(30)$ & 0.57 \\
\hline Independent $t$-test. & & &
\end{tabular}

Revising the outcome measures of both groups, mean sepsis days were significantly higher in the standard formula group (7.33 \pm 5.11 vs. $4.50 \pm 4.59$, $p<0.028)$. Mean ventilation days were comparable (6.77 \pm 5.11 vs. $5.17 \pm 5.75$ days $)$ in both groups ( $p=2.259)$. Length of PICU stay was not affected in both groups by type of formula (11.83 \pm 3.24 vs. $12.80 \pm 6.93, p=0.419)$. Moreover; mortality showed no difference between groups (30\% and $36 \%, p=0.57$ ) (Table III).

\section{Discussion}

Enteral feeding intolerance is common in critically ill patients [8]. Such intolerance is attributed to illness-associated intestinal dysfunction, such as impaired motility, inadequate digestion, and reduced absorption, as well as to side effects of treatment drugs. A high percentage of ICU patients on enteral nutrition have some symptoms of intolerance, that is, increased residual volume, bowel dilation, vomiting, or diarrhea $[9,10]$. About $80 \%$ of patients with head injury and $50 \%$ of mechanically ventilated and post-surgical patients have delayed gastric emptying [11]. Studies addressing the clinical advantages of using peptide-based formulas in critical illness to improve tolerance were carried out in adult patients and the results are controversial [5, 12, 13]. No recommendations are available on the use of polymeric or peptide-based formulas for pediatric, critically ill patients and, to our knowledge, no pediatric studies on this issue have been conducted.

This study showed marked improvement in enteral feeding tolerance among patients on the peptide-based formula compared to those on polymeric formulas and this was reflected in having significantly fewer interruptions of enteral feeding. Gastric residue, abdominal distension, vomiting and even hematemesis were significantly less often encountered in patients on the peptide-based formula. This might be explained by the pathophysiological changes of critical illness that impose deleterious effects on the digestive and absorptive functions of the critically ill gut, hence impairing the use of intact proteins, carbohydrates, and lipids.

These observations were contrary to studies on patients with acute pancreatitis, where abdomi- nal distention occurred in patients with a semi-elemental formula more than in patients receiving a polymeric formula, but studying a population with a specific inflammatory pathology such as acute pancreatitis might give a different perspective $[5,11]$.

A clear beneficial effect of better patient tolerance and minimal feeding interruptions is the significant weight gain observed among patients on the peptide-based formula. This was in contrast to patients on the polymeric formula, who showed further loss of weight along the study course. On the other hand, Tiengou et al., who carried out a similar study, found a weight reduction in both groups of patients but with a profound loss of weight in patients receiving polymeric formulas [5].

Interruptions of enteral feeding due to systemic illness, such as septic shock, and high doses of pressor agents and systemic bleeding as part of disseminated intravascular coagulopathy (DIC), or trials of extubation from invasive mechanical ventilation were encountered in a comparable way in all the studied population.

Analysis of the outcome measures in our current study revealed no difference between groups regarding length of stay (LOS) in the PICU. Revising the literature, we found variable effects impressions on effect of type of formula and ICU LOS. Tiengou et al. found statistically significantly higher LOS in patients receiving semi-elemental compared to patients receiving a polymeric formula [5]. Moreover, Vidigal et al. supported longer LOS in patients receiving a peptide-based formula. This was attributed to specifying the peptide-based formula to those patients with higher mortality and morbidity indices [4-6]. The same was observed in our study concerning days of mechanical ventilation, which were comparable in both groups of patients, whereas Vidigal et al. reported fewer days of mechanical ventilation in the group receiving a standard formula compared to patients on a peptide-based formula [4].

Significant reduction in sepsis days was observed among patients receiving the peptidebased formula in our study. We attribute this to better weight gain among this group and fewer feeding interruptions with subsequently less bac- 
terial translocation from the gut lumen to the systemic circulation and it might be due to the immune enhancement effect of the selected peptide-based formula.

As with other studies on the effect of polymeric and elemental formulas and patient outcomes, all results are controversial, with variable effects on sepsis or sepsis days and moreover on mortality. Tiengou et al. followed the occurrence of sepsis in two patient groups from day 1 to day 7 after starting enteral feeding with similar formulas as in our study and found no significant difference between groups [5]. Likewise, mortality in the current study was a reflection of the initial PRISM score of the patient groups rather than their type of enteral formula, and this also reflects randomization of the patient groups while other studies assign the elemental formulas to certain patient groups, mostly the more critical ones, and so observe higher mortalities [5].

The present study has several limitation. It was a single center study and therefore the enteral diet usage pattern could have been different if other ICUs had been included. We have not found data available on the extent to which peptide-based formulas are used in other PICU settings in different countries.

In conclusion, peptide-based formula feeding showed better tolerance than the standard polymeric formula in critically ill children. Minimal feeding interruption with better feeding tolerance boosted faster full caloric intake and improved weight gain. However, the choice of patients receiving a peptide-based formula needs to be further evaluated, especially in other pediatric critical care units with both surgical and medical contexts.

\section{Conflict of interest}

The authors declare no conflict of interest.

\section{References}

1. Campbel SM. An anthology of advances in enteral tube feeding formulations. Nutr Clin Pract 2006; 21: 411-5.

2. Pérez-Navero JL, Romillo DM, Cid JLH, et al. Nutrición artificial en las unidades de cuidados intensivos pediátricos. An Pediatr 2005; 62: 105-12.

3. Zaloga GP. Studies comparing intact protein, peptide, and amino acid formulas. In: Elemental Diets in Clinical Situations. Bounous G (ed.). CRC Press, Boca Raton 1993; 201-17.

4. Vidigal MVM, Leite HP, Nogueira PCK. Factors associated with peptide-based formula prescription in a pediatric intensive care unit. J Pediatr Gastroenterol Nutr 2012; 54: 620-3.

5. Tiengou LE, Gloro R, Pouzoulet J, et al. Semi-elemental formula or polymeric formula: Is there a better choice for enteral nutrition in acute pancreatitis? Randomized comparative study. J Parenter Enteral Nutr 2006; 30: 1-5.

6. Seres DS, Ippolito PR. Pilot study evaluating the efficacy, tolerance and safety of a peptide-based enteral formu- la versus a high protein enteral formula in multiple ICU settings (medical, surgical, cardiothoracic). Clin Nutr 2017; 36: 706-9.

7. World Health Organization (WHO). The WHO Child Growth Standards. http://www.who.int/ childgrowth/en.

8. Ukleja A. Altered GI motility in critically ill patients: current understanding of pathophysiology, clinical impact, and diagnostic approach. Nutr Clin Pract 2010; 25: 16-25.

9. Mentec H, Dupont H, Bocchetti M, Cani P, Ponche F, Bleichner G. Upper digestive intolerance during enteral nutrition in critically ill patients: frequency, risk factors, and complications. Crit Care Med 2001; 29: 1955-61.

10. Reintam A, Parm P, Kitus R, Kern H, Starkopf J. Gastrointestinal symptoms in intensive care patients. Acta Anaesthesiol Scand 2009; 53: 318-24.

11. Ritz MA, Fraser R, Tam W, Dent J. Impact s and patterns of disturbed gastrointestinal function in critically ill patients. Am J Gastroenterol 2000; 95: 3044-52.

12. Donald P, Miller E, Schirmer B, et al. Repletion of nutritional parameters in surgical patients receiving peptide versus amino acid elemental feedings. Nutr Res 1994; 14: 3-12.

13. Liu MY, Tang HC, Hu SH, Chang SJ. Peptide-based enteral formula improves tolerance and clinical outcomes in abdominal surgery patients relative to a whole protein enteral formula. World J Gastroint Surg 2016; 8: 700. 